\title{
Mathematical Modeling and Simulation of Enzyme Assisted Bioactive Compound Extraction from Allium Cepa Using Response Surface Methodology
}

\author{
K. Thirugnanasambandham \\ State University of Maringá, Department of Chemical Engineering,

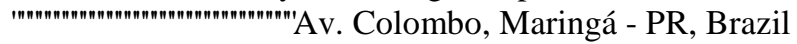 \\ E-Mail: thirusambath5@gmail.com
}

\begin{abstract}
In this present study, an attempt was made to investigate the enzyme assisted extraction process to extract the phenolic compounds from onion (Allium cepa) under various operating conditions such as temperature, extraction time and enzyme concentration. Three factors three level BoxBehnken response surface design (BBD) coupled with desired function methodlogy was used to optimize and model the extraction process. Optimum extracting conditions for the maximum phenloic compounds were determined and it was found to be: temperature of $40{ }^{\circ} \mathrm{C}$, extraction time of 16 hour and enzyme concentration of $2 \%$. Under these conditions, 9.25 $\%$ of phenolic compound was extracted. Extracted phenolic compounds can be regarded as the promising antioxidants to scavenge the DPPH free radicals.

Keywords: Phenolic compounds, Onion, Enzyme assisted extraction, Modelling, Optimzation
\end{abstract}

\section{INTRODUCTION}

Onions (Allium cepa) have been used for centuries in several societies against parasitic,fungal, bacterial and viral infections (Zou et al., 2008). Chemical characterisation of sulphur compounds in onions has allowed stating that they are the main active antimicrobial agents. There are many techniques to recover antioxidants from plants, such as Soxhlet extraction, maceration, supercritical fluid extraction, subcritical water extraction, microwave assisted extraction, ultrasound assisted extraction and enzyme assisted extraction. Among, various kind of extraction techniques, enzyme assisted extraction shows the advantages of non-toxic, maximum yield and reasanoble oprating cost over conventional extraction technique (Moure et al., 2000). However, extraction yield and antioxidant activity of extract not only depend on the extraction process variables such as temperature, extraction time and enzyme concentration. Optimization of these variables will pay the way to attain the higher yield and antioxidant activity of extract. Even though the dynamic characteristics of the enzyme assisted etraction process is very complicated, a number of attempts in developing an experimental-based optimization methodology may help to provide a better understanding of the process in terms of the effects of independent variables and their interactions on the dependent variable (Missang et al., 2005). Nowadays, optimization of extraction variables using stastical tool is emerging in excellent manner. One of the stastical tool used for optimization is response surface methodology (RSM) coupled with derringers desirability function method. The RSM is essentially a particular set of mathematical and statistical methods for designing experiments, building models, evaluating the effects of variables, and searching optimum conditions of variables to predict targeted responses (Ma et al., 2009). The RSM does not require a large number of runs and also does not require too many levels of the independent variables. An extensive literature survey shows that, extraction of polyphenolic compounds from onion using enzyme assisted extraction via RSM in not yet described. Therefore, finding new and safe antioxidants from onion is of great interest for applications in natural antioxidants, functional foods, and neutraceuticals. The basic aim of the research was to determine the total phenolic content and its antioxidant activity in onion using enzyme assisted extraction. Moreover, Response surface methodology (RSM) coupled with three factor three level Box-Behnken response surface design (BBD) was used to optimize and investigate the extraction process variables such as temperature, extraction time and enzyme concentration (Liu et al., 2010).

\section{MATERIALS AND METHODS}

\section{A. Materials and Chemicals}

The onion (Allium cepa L.) used in this study was purchased from Pungamuthur, Tamil, India. Cellulose enzyme was purchased from the local suppliers, Erode, India. FolinCiocalteu (FC) reagent, sodium carbonate anhydrous, gallic acid, sodium nitrite, sodium hydroxide, aluminum chloride anhydrous, 2,2- diphenyl-1-picrylhydrazyl (DPPH), trichloroacetic acid, were purchased from Sigma-Aldrich GmbH (Chennai, India). All other chemicals and reagents used were of analytical grade.

\section{B. Extraction of Phenol Compounds}

The fresh raw onions were cut into smaller pieces $(1 \mathrm{~cm} \times 1$ $\mathrm{cm} \times 1 \mathrm{~cm}$ ), weighed and added to distilled water with the solid:water ratio of 2:1. Then, the mixture of sample was 
stirred on the hot plate for 10 minutes, and allowed to cool down to room temperature. The $\mathrm{pH}$ was adjusted to $\mathrm{pH} 7$ by using $0.1 \mathrm{~N} \mathrm{NaOH}$ and $0.1 \mathrm{~N} \mathrm{HCl}$. The cellulose enzyme with different concentrations were added and the samples were extracted at different periods of time and temperature with constant shaking (200 rpm). After that, the samples were centrifuged $\left(10,000 \mathrm{rpm}, 30^{\circ} \mathrm{C}\right)$ for 10 minutes and the supernatants were collected, filtered into a beaker. Finally, the extracts were dried in a drying oven at $60^{\circ} \mathrm{C}$ and it is used for determination of phenolic content.

\section{Determination of Total Phenolic Contents in the Onion Extracts}

The concentration of phenolics in extracts was determined using spectrophotometric method. Based on the measured absorbance, the concentration of phenolics was read the content of phenolics in extracts was expressed in terms of gallic acid equivalent (mg of GAE/g of onion).

\section{Evaluation of Antioxidant Activity}

The ability of the onion extract to scavenge DPPH free radicals was assessed using antioxidant activity. The percentage inhibition of radicals was calculated using the following formula (Li et al., 2010)

$$
Y=\frac{A_{\text {Control }}-A_{\text {Sample }}}{A_{\text {Sample }}} * 100
$$

where $\mathrm{Y}$ is inhibition (\%). $\mathrm{A}_{\text {control }}$ is the absorbance of $\mathrm{DPPH}$ solution without extract and $\mathrm{A}_{\text {sample }}$ is the absorbance of sample with DPPH solution. The half-maximal inhibitory concentration $\left(\mathrm{IC}_{50}\right)$ was reported as the amount of antioxidant required to decrease the initial DPPH concentration by $50 \%$. The data were presented as mean values \pm standard deviation $(n=3)$.

\section{E. RSM Design}

In this present study, response surface methodology (RSM) coupled with Box-Behnken response surface experimental design (BBD) was employed to investigate the individual and interactive effects of process variables on the extraction of phenolic compounds from onion. Temperature (A), extraction time (B) and enzyme concentration (C) are selected as independent variables, whereas extraction of phenolic content (Y) is selected as response. Twenty nine experiments were designed with five replications. An empirical second-order polynomial model (Y) (response function) for predicting the optimal point was in the following form:

$$
Y=\beta_{0}+\sum_{j=1}^{k} \beta_{j} X_{j}+\sum_{j=1}^{k} \beta_{j j} X_{j}^{2}+\sum_{i} \sum_{<j=2}^{k} \beta_{i j} X_{i} X_{j}+e_{i}
$$

Adequcy of developed mathematical models were investigated by the pareto analysis of variance (ANOVA) and developed models was used to plot the response surface contour graphes in order to study the interactive effect of independent variables on the responses All the statistical analysis was done using Design- Expert 8.0.7.1 (State-Ease Inc., Minneapolis, MN, USA) package. The detailed methology used in this study was reported elsewhere (Kumaran et al., 2006).

\section{RESULTS AND DISCUSSION}

\section{A. Mathematical Modelling}

Process variables and their ranges are shown in Table I. For the investigation of the effect of extraction conditions on the phenolic content, batch experiments were performed according to BBD design and the results are tabulated in Table II. Different response functions such as linear, interactive, quadratic and cubic models were used to correlate the experimental data and to obtain the regression equation. To decide about the adequacy of the model three different tests namely sequential model sum of squares and model summary statistics were carried out in the present study and the results are presented in Table III. Experimental data were used for determining of the response function coefficients for each independent variable (Ismail et al., 2010). The response function with the determined coefficients for the extraction yield of phenolic content as follows

$\mathrm{Y}=$ 8.96-0.36A+0.21B+0.73C+1.79AB-0.92AC-1.09BC-

$2.26 \mathrm{~A}^{2}-0.96 \mathrm{~B}^{2}-1.21 \mathrm{C}^{2}$

Where, Y is extraction yield of phenolic content (\%); A, B and $\mathrm{C}$ are temperature, extraction time and enzyme concentration respectively.

The statistical significance of the response function was checked by F-test, and the ANOVA results for response surface quadratic model and model terms are summarized in Table 4. The model F value and very low probability value (0.0001) indicated that the model was statistically significant and model equation can adequately be used to describe the response. Adequcy of the developed mathematical model examined as follows, a normal distribution function was then fit to the studentized residuals. Then, the studentized residual predicted by the best-fit normal distribution was plotted against the experimentally obtained studentized residual in Fig.1a. Fig. $1 \mathrm{~b}$ plots was the studentized residuals versus predicted. This plot is expected to be a random scatter, indicating that the variation in the original observations is not related to the value of the response and it further indicates that the suggested model is an appropriate description of the process. Further, diagnostic plots such as predicted versus actual (Fig. 1c) help us to evaluate the model suitability and find out the relationship between predicted and experimental values. The data points on this plot lie reasonably close to the straight line and indicate that an adequate agreement between real data and the data obtained from the model (Gutteridge et al., 2007). 


\section{B. Effect of Process Variables on the Extraction of Phenolic Compounds}

The regression model (Eq. (3)) can be used to predict the enzyme assisted extraction of phenolic compounds (response) for the different values of the tested variables and to identify the major interactive effects between the test variables from the circular or elliptic nature of the contours. The 3-dimensional response surfaces were plotted based on Eq. (5) and these response surfaces by computer modeling show that the center point derived from one-by-one variations (Fig.2).

\section{Effect of Temperature}

Temperature is one of the crucial extraction parameter in the extraction of phenolic compounds from onion using enzyme assisted extraction. In order to investigate the effect of temperature on extraction yield of phenolic compounds, experiments were carried out in various temperature (30-50 ${ }^{\circ} \mathrm{C}$ ) and the results are shown in Fig.2a-b. From the results, it is observed that, the extraction yield of phenolic compound is increased linearly with increasing temperature upto $45{ }^{\circ} \mathrm{C}$. However, temperature beyond $45{ }^{\circ} \mathrm{C}$ shows negative impact on extraction yield of phenolic compounds (Guo et al., 2011).

\section{Effect of Extraction Time}

Extraction time is one of the key parameter which influences the enzyme assisted extraction significantly. To exmine its effect on the extraction yield of phenolic compound, experiments were carried out in various extraction time (10-24 hours) and the results are shown in Fig. 2. From the Fig.2b-c, it is found that, the extraction yield of phenolic compound is increased rapidly with increasing the extraction time upto 18 hour. Beyond 18 hour of extraction time shows the negligible effect on the extraction yield of phenolic compound from onion (Gong et al., 2012).

\section{Effect of Enzyme Concentration}

Enzyme concentration is a important parameter influences the extraction yield of polyphenloic compound from onion using enzyme assisted extraction. So that, experiments were carried out to study the effect of enzyme concentration (0.8$2.8 \%$ ) on the extraction yield of phenolic compound. From the results (Fig. 2a-c), it is observed that, the extraction yield of phenolic compound is increased linearly with increasing enzyme concentration from 0.8 to $2 \%$. However, enzyme concentration beyond $2 \%$ resulted in negligible effect on the extraction yield of phenolic compound (Falleh et al., 2008).

\section{Multi Response Optimization and Validation}

After analyzing the polynomial equation depicting the effect of independent variables on the response, optimization process was carried out. From the results, it is found that optimum condition for the maximum yield of phenolic compound found to be as follows: temperature of $40{ }^{0} \mathrm{C}$, extraction time of 16 hour and enzyme concentration of 2 \%. Under these conditions, $9.25 \%$ of phenolic compounds was extracted and it is validated (9.18\%) used by conducting the additional experiment in the above mentioned opimum conditions in triplicates.

\section{Antioxidant activity of extracted phenolic compound}

Fig.3 shows the DPPH scavenging activities of the extracts in a concentration-dependent manner. The extract obtained by $100 \%$ ethanol yielded the highest $\mathrm{DPPH}$ radical scavenging activity at concentration range of $100 \mu \mathrm{g} / \mathrm{mL}$. However, at concentrations ranging from $175 \mu \mathrm{g} / \mathrm{mL}$ to 200 $\mu \mathrm{g} / \mathrm{mL}$, its DPPH radical scavenging activity is not significantly different from those of the other extracts (Chen et al., 2011). The $\mathrm{IC}_{50}$ of a compound is inversely related to its antioxidant capacity, as it expresses the amount of antioxidant required to decrease the DPPH concentration by $50 \%$, which is obtained by interpolation from a linear regression analysis. A lower $\mathrm{IC}_{50}$ value indicates a higher antioxidant activity of a the extracted compound (Chen et al., 2008).

TABLE I PROCESS VARIABLES AND THEIR RANGES

\begin{tabular}{|l|c|c|c|}
\hline \multicolumn{1}{|c|}{ Level } & $\mathbf{- 1}$ & $\mathbf{0}$ & $\mathbf{1}$ \\
\hline Temperature $\left({ }^{\mathrm{O}} \mathrm{C}\right)$ & 30 & 40 & 50 \\
\hline Extraction time (hour) & 10 & 17 & 24 \\
\hline Enzyme concentration (\%) & 0.8 & 1.6 & 2.4 \\
\hline
\end{tabular}

TABLE II BBD DESIGN OF RESULTS

\begin{tabular}{|c|c|c|c|c|}
\hline S.No. & A & B & C & Y \\
\hline 1 & 40 & 17 & 1.6 & 8.96 \\
\hline 2 & 40 & 17 & 1.6 & 8.96 \\
\hline 3 & 40 & 17 & 1.6 & 8.96 \\
\hline 4 & 50 & 17 & 0.8 & 5.28 \\
\hline 5 & 50 & 10 & 1.6 & 3.62 \\
\hline 6 & 30 & 17 & 2.4 & 7.54 \\
\hline 7 & 40 & 24 & 2.4 & 6.84 \\
\hline 8 & 50 & 17 & 2.4 & 4.58 \\
\hline 9 & 40 & 10 & 0.8 & 4.55 \\
\hline 10 & 40 & 17 & 1.6 & 8.96 \\
\hline 11 & 30 & 17 & 0.8 & 4.58 \\
\hline 12 & 40 & 17 & 1.6 & 8.96 \\
\hline 13 & 40 & 10 & 2.4 & 8.54 \\
\hline 14 & 30 & 10 & 1.6 & 7.52 \\
\hline 15 & 30 & 24 & 1.6 & 4.28 \\
\hline 16 & 50 & 24 & 1.6 & 7.54 \\
\hline 17 & 40 & 24 & 0.8 & 7.22 \\
\hline & & & \\
\hline
\end{tabular}


TABLE III SEQUENTIAL MODEL SUM OF SQUARES FOR RESPONSES

\begin{tabular}{|c|c|c|c|c|c|c|}
\hline Source & Sum of Squares & Df & Mean Square & F Value & Prob $>$ F & Remarks \\
\hline \multicolumn{7}{|c|}{ Sequential model sum of squares for total phenolic content } \\
\hline Mean & 803.72 & 1.00 & 803.72 & & & \\
\hline Linear & 5.70 & 3.00 & 1.90 & 0.44 & 0.7278 & \\
\hline $2 \mathrm{FI}$ & 20.94 & 3.00 & 6.98 & 1.99 & 0.1797 & \\
\hline Quadratic & 34.54 & 3.00 & 11.51 & 142.29 & $<0.0001$ & Suggested \\
\hline Cubic & 0.57 & 3.00 & 0.19 & 63660000.00 & $<0.0001$ & Alised \\
\hline Residual & 0.00 & 4.00 & 0.00 & & & \\
\hline Total & 865.46 & 17.00 & 50.91 & & & \\
\hline \multicolumn{7}{|c|}{ Model summary statistics } \\
\hline Model & Std.Dev. & $\mathrm{R}^{2}$ & Adjusted $\mathrm{R}^{2}$ & Predicted $\mathrm{R}^{2}$ & PRESS & Remarks \\
\hline \multicolumn{7}{|c|}{ Total phenolic content } \\
\hline Linear & 2.0763 & 0.0923 & -0.1172 & -0.5608 & 96.4 & \\
\hline $2 \mathrm{FI}$ & 1.8736 & 0.4314 & 0.0903 & -0.5110 & 93.3 & \\
\hline Quadratic & 0.2844 & 0.9908 & 0.9790 & 0.8532 & 9.0620 & Suggested \\
\hline Cubic & 0.0000 & 1.0000 & 1.0000 & & + & Aliased \\
\hline
\end{tabular}

TABLE IV ANOVA RESULTS FOR RESPONSE

\begin{tabular}{|c|c|c|c|c|c|}
\hline Source & Sum of Squares & df & Mean square & F value & P-value \\
\hline Model & 61.18 & 9.0000 & 6.79727 & 84.0095 & $<0.0001$ \\
\hline A & 1.05 & 1.0000 & 1.05125 & 12.9927 & 0.0087 \\
\hline B & 0.34 & 1.0000 & 0.34031 & 4.20603 & 0.0794 \\
\hline $\mathrm{C}$ & 4.31 & 1.0000 & 4.30711 & 53.2329 & 0.0002 \\
\hline $\mathrm{AB}$ & 12.82 & 1.0000 & 12.8164 & 158.402 & $<0.0001$ \\
\hline $\mathrm{AC}$ & 3.35 & 1.0000 & 3.3489 & 41.3901 & 0.0004 \\
\hline $\mathrm{BC}$ & 4.77 & 1.0000 & 4.77423 & 59.0061 & 0.0001 \\
\hline$A^{2}$ & 21.43 & 1.0000 & 21.4344 & 264.914 & $<0.0001$ \\
\hline $\mathrm{B}^{2}$ & 3.91 & 1.0000 & 3.9108 & 48.3347 & 0.0002 \\
\hline $\mathrm{C}^{2}$ & 6.15 & 1.0000 & 6.1519 & 76.0332 & $<0.0001$ \\
\hline $\mathrm{CV}$ & \multicolumn{5}{|c|}{4.14} \\
\hline AP & \multicolumn{5}{|c|}{20.56} \\
\hline PRESS & \multicolumn{5}{|c|}{12.02} \\
\hline Mean & \multicolumn{5}{|c|}{6.58} \\
\hline $\mathrm{R}^{2}$ & \multicolumn{5}{|c|}{0.9868} \\
\hline Adj-R ${ }^{2}$ & \multicolumn{5}{|c|}{0.9699} \\
\hline
\end{tabular}

\section{CONCLUSION}

In this present study enzyme assisted extraction of phenolic compounds was carried out to optimize and determine the effect of various parameters such as temperature, extraction time and enzyme concentration. RSM coupled with BBD was employed to study and optimize the process variables on the extraction of phenolic compounds. From the results, it was observed that all the process variables have significant effects on the phenolic compound extraction and the quadratic model was developed for predicting the response. The highest phenolic compound yield (9.25\%) was achieved at the optimum conditions as follows: temperature of $40{ }^{\circ} \mathrm{C}$, extraction time of 16 hour and enzyme concentration of $2 \%$. The DPPH radical scavenging activity of extracted phenoilc compound is highly significant. 

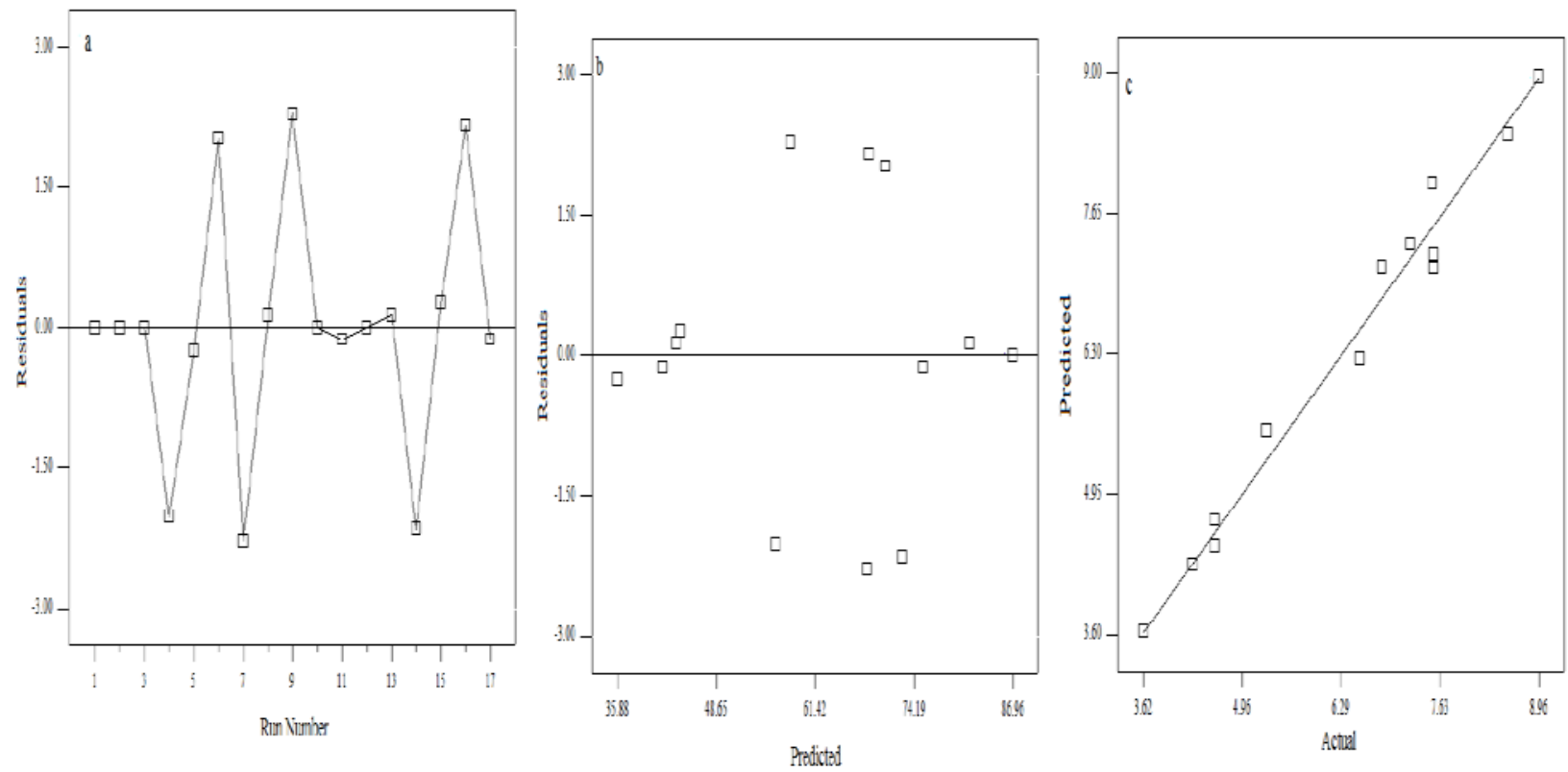

Fig.1 Model Adequacy Plots

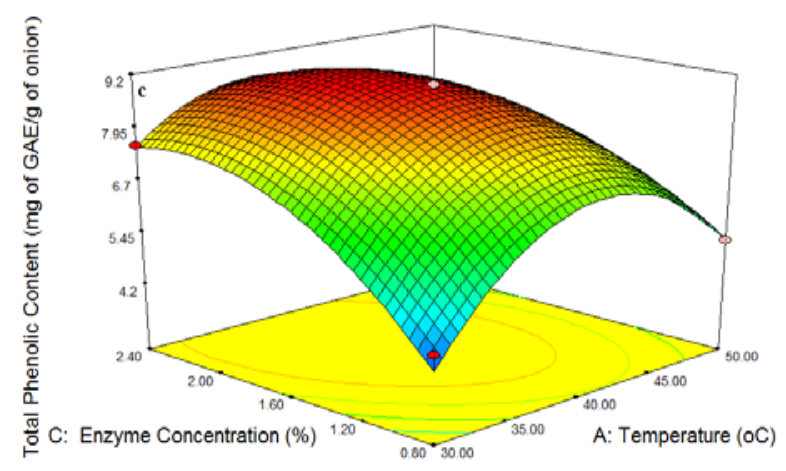

Fig. 2 Response Surface Plots representing the effect of Process Variables on total Phenolic content.

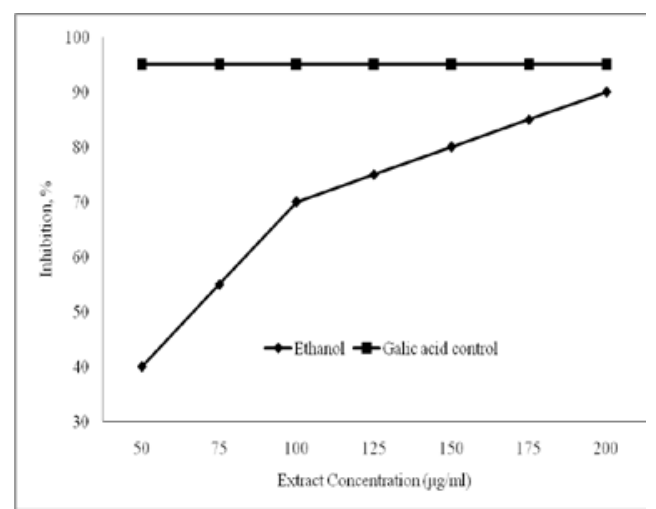

Fig.3 DPPH Scavenging Activity of the Extract.

\section{REFERENCES}

[1] S. Chen, X. H. Xing, J. J. Huang and M. S. Xu, "Enzyme-assisted extraction of flavonoids from Ginkgo Biloba leaves: improvement effect of Flavonol Transglycosylation catalyzed by Penicillium decumbens cellulose” Enzyme Microb. Techn., Vol. 48, pp. 100-105, 2011.

[2] Y. Chen, M. Y. Xie, S. P. Nie, C. Li and Y. X. Wang, "Purification, composition analysis and antioxidant activity of a polysaccharide from the fruiting bodies of Ganoderma atrum", Food Chem., Vol. 107, pp. 231-241, 2008.

[3] J. E. N. Dolatabadi and S. Kashanian, "A review on DNA interaction with synthetic phenolic food additives”, Food Res. Int., Vol. 43, pp. 1223-1230, 2010.

[4] H. Falleh, R. Ksouri, K. Chaieb, N. Karray-Bouraoui, N. Trabelsi, M. Boulaaba and C. Abdelly, "Phenolic composition of Cynara cardunculus L. organs, and their Biological Activities", C. R. Biol., Vol. 331, 372-379, 2008.

[5] Y. Gong, Z. Q. Hou, Y. X. Gao, Y. S. Xue, X. Liu and G. M. Liu, "Optimization of extraction parameters of bioactive components from defatted Marigold (Tagetes erecta L.) residue using response surface methodology”, Food Bioprod. Process., Vol. 90, pp. 9-16, 2012.

[6] T. Guo, L. Wei, J. Sun, C. L. Hou and L. Fan, "Antioxidant activities of extract and fractions from Tuber indicum Cooke \& Massee”, Food Chem., Vol. 127, pp. 1634-1640 2011.

[7] J. M. C. Gutteridge, "Ferrous-salt-promoted damage to deoxyribose and benzoate: The Increased effectiveness of hydroxyl-radical scavenger in the presence of EDTA", Biochem. J., Vol. 243, pp. 709714, 1987.

[8] S. Hemwimon, P. Pavasant and A. Shotipruk, "Microwave-assisted extraction of antioxidative anthraquinones from roots of morinda citrifolia”, Sep. Purif. Techn., Vol. 54, pp. 44-50, 2007.

[9] M. Ismail, A. A. Mariod, R. M. Ibrahim and N. Ismail, "Antioxidant activities of phenolic rich fractions (PRFs) obtained from black mahlab (Monechma ciliatum) and white mahlab (Prunus mahaleb) seedcakes”, Food Chem., Vol. 118, pp. 120-127, 2010.

[10] A. Kumaran and J. R. Karunakaran, "Antioxidant and free radical scavenging activity of an aqueous extract of Coleus aromaticus", Food Chem., Vol. 97, pp. 109-114, 2006.

[11] J. Li, Y. G. Zu, Y. J. Fu, Y. C. Yang, S. M. Li, Z. N. Li and M. Wink, "Optimization of microwave-assisted extraction of triterpene saponins from defatted residue of yellow horn (Xanthoceras sorbifolia Bunge.) kernel and evaluation of its antioxidant activity”, Innov. Food Sci. Emerg., Vol. 11, pp. 637-643, 2010.

[12] W. Liu, Y. J. Fu, Y. G. Zu, M. H. Tong, N. Wu, X. L. Liu and S. Zhang, "Supercritical carbon dioxide extraction of seed oil from Opuntia dillenii Haw and its antioxidant activity”, Food Chem., Vol. 114, pp.334-339, 2009. [Online]. Available: https://doi.org/10.1016/j.foodchem.2017.06.150. 
[13] Y. Liu, X. M. Sun and B. H. Li, “Adsorption of $\mathrm{Hg}^{2+}$ and $\mathrm{Cd}^{2+}$ by ethylenediamine modified peanut shells", Carbohydr. Polym., Vol. 81, pp. 335-339, 2010.

[14] Y. Q. Ma, J. C. Chen, D. H. Liu and X. Q. Ye, "Simultaneous extraction of phenolic compounds of citrus peel extracts, Effect of ultrasound”, Ultrason. Sonochem., Vol. 16, pp. 57-62, 2009. [Online]. Available:https://doi.org/10.1016/j.foodchem.2017.06.150.

[15] C. E. Missang, P. Massiot, A. Baronand, J. F. Drilleau, "Effect of oxidative browning of apple pulp on the chemical and enzymatic extraction of cell wall polysaccharides”, Carbohydr.Polym. Vol. 20, pp. 131-138, 1993.

[16] A. Moure, D. Franco, J. Sineiro, H. Dominguez, M. J. Nunezand J. M. Lema, "Evaluation of extracts from Gevuina hulls as antioxidants”, J. Agric. Food Chem., Vol. 48, pp. 3890-3897, 2000.

[17] L. Quanhong and F. Caili, "Application of response surface methodology for extraction optimization of germinant pumpkin seeds protein”, Food Chemistry, Vol. 92, pp. 701-706, 2005.
[18] E. M. Silva, H. Rogez and Y. Larondelle, “Optimization of extraction of phenolics from Inga edulis leaves using response surface methodology”, Sep. Purif. Techn., Vol. 55, pp. 381-3, 2007

[19] W. Wang, C. M. Xu and X. L. Cao, "Optimization of microwaveassisted extraction of polysaccharide from Morus alba L. by response surface methodology”, J. Beijing Technol.Bus. Univ. (Nat. Sci. Ed.) Vol. 27, No. 4, pp. 6-9, 2009.

[20] T. Xu and X. Q. Liu, "Peanut shell activated carbon: characterization, surface modification and adsorption of $\mathrm{Pb}^{2+}$ from aqueous solution", Chin. J. Chem. Eng., Vol. 16, pp. 401-406, 2008.

[21] C. Zou, Y. M. Du, Y. Li, J. H.Yang, T. Feng, L. Zhang and J. F. Kennedy, "Preparation of lacquer polysaccharide sulfates and their antioxidant activity in vitro", Carbohydr. Polym., Vol. 73, pp. 322331, 2008. 